\title{
Plasma glial fibrillary acidic protein detects Alzheimer pathology and predicts future conversion to Alzheimer dementia in patients with mild cognitive impairment
}

\author{
Claudia Cicognola ${ }^{1,2^{*}}$ (D), Shorena Janelidze ${ }^{1}$, Joakim Hertze ${ }^{2}$, Henrik Zetterberg ${ }^{3,45,6}$, Kaj Blennow ${ }^{3,4}$,
} Niklas Mattsson-Carlgren ${ }^{1,7,8}$ and Oskar Hansson ${ }^{1,2^{*}}$

\begin{abstract}
Introduction: Plasma glial fibrillary acidic protein (GFAP) is a marker of astroglial activation and astrocytosis. We assessed the ability of plasma GFAP to detect Alzheimer's disease (AD) pathology in the form of AD-related amyloid- $\beta(A \beta)$ pathology and conversion to $A D$ dementia in a mild cognitive impairment $(\mathrm{MCl})$ cohort.

Method: One hundred sixty $\mathrm{MCl}$ patients were followed for 4.7 years (average). AD pathology was defined using cerebrospinal fluid (CSF) A $42 / 40$ and A $342 /$ total tau (T-tau). Plasma GFAP was measured at baseline and follow-up using Simoa technology.

Results: Baseline plasma GFAP could detect abnormal CSF A $42 / 40$ and CSF A $342 /$-tau with an AUC of 0.79 (95\% $\mathrm{Cl} 0.72-0.86)$ and 0.80 (95\% Cl 0.72-0.86), respectively. When also including APOE $\varepsilon 4$ status as a predictor, the accuracy of the model to detect abnormal CSF A $42 / 40$ status improved (AUC $=0.86, p=0.02$ ). Plasma GFAP predicted subsequent conversion to AD dementia with an AUC of 0.84 (95\% Cl 0.77-0.91), which was not significantly improved when adding APOE $\varepsilon 4$ or age as predictors to the model. Longitudinal GFAP slopes for A $\beta$ positive and $\mathrm{MCl}$ who progressed to dementia (AD or other) were significantly steeper than those for $A \beta$-negative $(p=0.007)$ and stable $\mathrm{MCl}(p<0.0001)$, respectively.
\end{abstract}

Conclusion: Plasma GFAP can detect AD pathology in patients with $\mathrm{MCl}$ and predict conversion to AD dementia.

Keywords: Blood biomarkers, GFAP, Alzheimer's disease, Mild cognitive impairment

\section{Introduction}

By 2050, more than 150 million people worldwide are estimated to be affected by dementia, with Alzheimer's disease (AD) causing up to $70 \%$ of all cases [1]. AD dementia is still largely a clinical diagnosis, although amyloid- $\beta(A \beta)$ in brain starts decades before the symptoms appear [2]. $A \beta$ plaques cause astrogliosis, i.e., functional and

\footnotetext{
* Correspondence: claudia.cicognola@med.lu.se; oskar.hansson@med.lu.se ${ }^{1}$ Clinical Memory Research Unit, Department of Clinical Sciences, Lund University, Lund, Sweden

Full list of author information is available at the end of the article
}

morphological changes in the surrounding astrocytes, which are glial cells involved in brain signaling, modulation of synapses, transport of nutrients, homeostasis, and structural support $[3,4]$. Animal and cell studies have shown the presence of astrogliosis around $A \beta$ plaques and the involvement of reactive astrocytes in $A \beta$ production and toxicity [5-8]. Studies conducted with PET tracers targeting astrocytes have shown that astrogliosis is an early feature in the pathological cascade of $\mathrm{AD}$, which decreases over the course of disease as opposed to the increase of $A \beta$ plaque load [9-11]. 
Glial fibrillary acidic protein (GFAP) is expressed in the cytoskeleton of astrocytes and has been found significantly increased in CSF in AD and other neurodegenerative diseases compared to healthy controls [1215]. GFAP has also been recently measured in plasma and serum, where it was found increased in different neurological conditions, including AD [16-24]. Different studies have shown that higher concentrations of plasma GFAP were associated to amyloid-PET positivity and worse outcomes in global cognition [22, 24-27]. Even though previous studies suggest that blood GFAP levels are elevated in $\mathrm{AD}$ and can identify an amyloid-PET positive status, only one study has measured GFAP in cognitively normal subjects followed over time for conversion to dementia (of any kind) [27]. Higher baseline GFAP, measured in serum, was associated to increased risk of dementia, but no significant difference was seen in the change over time of GFAP levels between the cognitively normal and dementia groups [27]. No studies have been done in patients with mild cognitive impairment (MCI) investigating whether plasma GFAP can predict future conversion to AD dementia, specifically.

In this study, our aim was to evaluate plasma GFAP as a potential plasma biomarker of $\mathrm{AD}$ in MCI patients, and assess its association with $\mathrm{AD}$-related $\mathrm{A} \beta$ pathology and conversion to AD dementia. Early identification of patients that are more likely to have worse cognitive outcome could positively affect their clinical management and help fast-track the diagnostic process; moreover, these patients could be selected for inclusion in clinical trials with disease-modifying drugs currently under development. The study included 160 subjects with a baseline clinical diagnosis of $\mathrm{MCI}$, followed for an average of 4.7 years. CSF and plasma samples were collected at baseline and follow-up. Patients were divided according to clinical diagnosis into the groups stable MCI (those who did not progress to AD dementia or other dementias), MCI-AD (those who progressed to dementia due to $\mathrm{AD}$ ), and $\mathrm{MCI}$-other (those who progressed to dementia due to other non-AD diseases). Each diagnostic groups was further stratified in $A \beta$-positive and $A \beta$ negative based on CSF $A \beta 42 / 40$ and $A \beta 42 /$ total tau (Ttau) ratios.

\section{Materials and methods $\mathrm{MCl}$ clinical cohort}

The present study includes 160 patients referred to the Memory Clinic at Skåne University Hospital, Malmö. CSF data from the cohort have previously been published [28]. At the clinical baseline visit, physicians with an expertise in cognitive disorders performed a thorough physical, neurological, and psychiatric examination, as well as a clinical interview focusing on cognitive symptoms and ADL function. Furthermore, analysis of $A P O E$ genotype was performed.

Patients with MCI at baseline had to fulfill the criteria by Petersen, including (1) memory complaint, preferably corroborated by an informant; (2) objective memory impairment adjusted for age and education, as judged by the physician; (3) preservation of general cognitive functioning, as determined by the clinician's judgment based on a structured interview with the patient and a Mini Mental Status Examination (MMSE) score greater than or equal to 24; (4) zero or minimal impairment of daily life activities; and (5) not fulfilling the DSM-IIIR criteria for dementia [29]. Patients with other causes of cognitive impairment, including subdural hematoma, brain tumor, CNS infection, schizophrenia, major depressive episode, and current alcohol abuse were excluded. However, MCI subjects were allowed to show signs of white matter changes or silent brain infarcts, because these changes are frequent in elderly subjects with or without cognitive deficits. Similarly, MCI patients with mild to moderate depressive symptoms and low plasma concentrations of vitamin B12 or folate were not excluded. The included patients with MCI at baseline subsequently developed a certain type of dementia or remained cognitively stable for an average of 4.7 years. The patients with MCI who received a diagnosis of $\mathrm{AD}$ during clinical follow-up were required to meet the DSM-IIIR criteria for dementia and the criteria of probable AD defined by NINCDSADRDA [30]. Subjects who during follow-up were diagnosed as having vascular dementia $(\mathrm{VaD})$ fulfilled the DSM-IIIR criteria of dementia and the requirements for probable $\mathrm{VaD}$ by NINDS-AIREN [31]. The consensus criteria by McKeith and coworkers were applied when diagnosing dementia with Lewy bodies (DLB) [32]. Subjects with progressive supranuclear palsy (PSP) fulfilled the criteria by Litvan et al. [33] and Höglinger et al. [34]. The clinical diagnoses of all patients were reviewed by a consensus group consisting of three medical doctors with special interest in cognitive disorders. The study was approved by the Ethics Committee at the University of Lund and the patients and/or their relatives gave their informed consent (for research). Patients were divided according to clinical diagnosis into the groups stable $M C I$ (those who did not progress to $\mathrm{AD}$ dementia or other dementias, $n=79$ ), MCI-AD (those who progressed to dementia due to $\mathrm{AD}, n=47)$, and MCI-other (those who progressed to dementia due to other diseases: $n=34$, of which $\mathrm{VaD}=25, \mathrm{DLB}=4, \mathrm{PSP}=3$, other neurological diseases $=2$ ).

\section{Plasma and CSF sampling}

Blood and CSF samples were collected in the morning during the same visit, with participants non-fasting. Blood was collected in six EDTA-plasma tubes and 
centrifuged $\left(2000 g,+4{ }^{\circ} \mathrm{C}\right)$ for $10 \mathrm{~min}$. Following centrifugation, plasma was aliquoted into $1.5-\mathrm{ml}$ polypropylene tubes ( $1 \mathrm{ml}$ plasma in each tube) and stored at $-80^{\circ} \mathrm{C}$ within 30-60 min of collection. CSF was collected by lumbar puncture and stored at $-80^{\circ} \mathrm{C}$ in polypropylene tubes following the Alzheimer's Association flow chart for lumbar puncture and CSF sample processing [35].

\section{Plasma and CSF analysis}

Plasma GFAP was measured with Simoa GFAP Discovery kits for SR-X (Quanterix', Billerica, MA, USA) according to the manufacturer's instructions. The levels of CSF total tau (T-tau) and tau phosphorylated at Thr181 (P-tau181) were determined using xMAP technology as previously described [36]. CSF $A \beta 40$ and $A \beta 42$ levels were analyzed by electrochemiluminescence technology (Meso Scale Discovery, Gaithersburg, Maryland, USA), using the MS6000 Human Abeta 3-Plex Ultra-Sensitive Kit, following the manufacturer's recommendation. An A $\beta$-positive subject was defined as having a CSF A $442 /$ 40 value below 0.07 . The cut-off was previously calculated by Youden index as the best to separate AD patients from cognitively healthy controls [28]. Groups were also divided in CSF A $442 / \mathrm{T}$-tau-positive and A $\beta 42 /$ T-tau-negative groups using a cut-off previously calculated in the same cohort using Youden index [28]. A cut-off of 7.3 was the best to separate AD patients from healthy controls.

\section{Statistical analysis}

Analyses were performed using SPSS v.24 (IBM) and R v.3.5.3. Data were visualized using either Prism 8.4 (Graphpad) or R. Group differences were assessed in univariate general linear models, adjusted for age and sex and post hoc least significant difference (LSD) tests for pairwise group comparisons. Biomarkers values were
LOG10 transformed prior to this analysis. Diagnostic accuracies were assessed with receiver operating characteristic (ROC) curve analysis and binary logistic regression models. Akaike information criterion (AIC) was calculated for each logistic regression model. Sensitivities and specificities for the biomarkers were calculated at Youden index thresholds. Linear mixed-effect model with random intercept adjusted for age and sex was used to determine biomarker slopes over time and differences between groups. Spearman $r$ was used to measure correlations between biomarkers. $P$ values $<0.05$ were considered significant.

\section{Results}

Group sizes, age, and gender distribution for subgroups are shown in Table 1 . Of these 160 patients with MCI, 159 had GFAP measurements at baseline and one case had only the follow-up measurement of GFAP. One hundred and ten subjects had both baseline and followup measurements. The average length of the follow-up was 4.7 years.

GFAP baseline values in A $\beta$-negative $\mathrm{MCI}$ subjects correlated significantly with age $(r=0.57, p<0.0001)$ and CSF A $\beta 42 / 40(r=-0.33, p=0.003)$ (Table 2). In A $\beta$ positive MCI patients, GFAP also correlated with CSF T-tau $(r=0.29, p=0.01)$ and CSF P-tau181 $(r=0.28, p=$ 0.01) (Table 2).

\section{Plasma GFAP for detection of AD pathology}

We first analyzed the whole cohort comparing plasma GFAP in groups defined according to their CSF A $\beta 42 / 40$ and $A \beta 42 / T$-tau status. Plasma GFAP levels at baseline were significantly different between CSF A $\beta 42 / 40$-positive and CSFA $\beta 42 / 40$-negative groups as well as between CSF A $\beta 42 / T$-tau-positive and CSF A $\beta 42 / T$-tau-negative groups (both $p<0.0001$ ) (Fig. 1a, b). We then compared

Table 1 Demographic and clinical data

\begin{tabular}{|c|c|c|c|c|c|}
\hline & Stable $\mathrm{MCl}(\mathrm{A} \beta-)$ & Stable $\mathrm{MCl}(\mathrm{A} \beta+)$ & $\mathrm{MCl}-\mathrm{AD}(\mathrm{A} \beta+)$ & $\mathrm{MCl}$-other $(\mathrm{A} \beta-)$ & $\mathrm{MCl}$-other $(\mathrm{A} \beta+)$ \\
\hline \multicolumn{6}{|l|}{ Characteristics } \\
\hline$N$ & 58 & 21 & 47 & 25 & 9 \\
\hline Age & $69(8)$ & $69(6)$ & $76(7)$ & $73(7)$ & $74(6)$ \\
\hline Gender (\% female) & $55 \%$ & $48 \%$ & $75 \%$ & $44 \%$ & $33 \%$ \\
\hline APOE genotype (\% 1 or 2 ع4 alleles) & $29 \%$ & $81 \%$ & $81 \%$ & $44 \%$ & $78 \%$ \\
\hline \multicolumn{6}{|l|}{ CSF } \\
\hline$A \beta 42 / 40$ & $0.10(0.02)$ & $0.05(0.01)$ & $0.05(0.01)$ & $0.10(0.02)$ & $0.06(0.01)$ \\
\hline T-tau (pg/mL) & $68(29)$ & $111(72)$ & $148(70)$ & $90(43)$ & $75(33)$ \\
\hline P-tau181 (pg/mL) & $26(11)$ & $40(21)$ & $54(22)$ & $30(12)$ & $33(11)$ \\
\hline \multicolumn{6}{|l|}{ Plasma } \\
\hline GFAP baseline $(\mathrm{pg} / \mathrm{mL})$ & $36(17)$ & $46(25)$ & $67(24)$ & $42(16)$ & $52(11)$ \\
\hline GFAP follow-up (pg/mL) & $43(16)$ & $65(41)$ & $94(34)$ & $67(27)$ & $78(34)$ \\
\hline
\end{tabular}

Values are expressed as mean (SD). Abbreviations: $A \beta \beta$-amyloid, $A \beta+A \beta$ positive, $A \beta-A \beta$ negative, CSF cerebrospinal fluid, GFAP glial fibrillary acidic protein 
Table 2 Correlations between plasma GFAP baseline levels and age, CSF Aß42/40, CSF T-tau, and CSF P-tau181

\begin{tabular}{llllll}
\hline & & Age & $\mathbf{A} \boldsymbol{\beta}$ 42/40 & T-tau & $\mathbf{P}$-tau181 \\
\hline $\mathbf{A} \boldsymbol{\beta}-$ & $r$ & 0.57 & -0.33 & 0.06 & -0.03 \\
& $p$ & $<0.0001$ & 0.003 & 0.61 & 0.79 \\
$\mathbf{A} \boldsymbol{\beta}+$ & $r$ & 0.46 & -0.18 & 0.29 & 0.28 \\
& $p$ & $<0.0001$ & 0.13 & 0.01 & 0.01 \\
\hline
\end{tabular}

$r$ Spearman's $r, A \beta+A \beta$ positive, $A \beta-A \beta$ negative

those patients who progressed to dementia due to $\mathrm{AD}$ (MCI-AD) to those who remained stable (stable $\mathrm{MCI}$ ) and those who progressed to dementia due to other diseases (MCI-other). The last two groups were subdivided in $A \beta$-positive or $A \beta$-negative according to the presence or absence of biomarker evidence of brain amyloidosis based on CSF A $\beta 42 / 40$. The MCI-AD group had significantly higher plasma GFAP concentrations than $A \beta$ negative cognitively stable $\mathrm{MCI}$ and $\mathrm{A} \beta$-negative MCIother (both $p<0.0001$ ) (Fig. 1c). A $\beta$-positive stable MCI and $\mathrm{A} \beta$-positive $\mathrm{MCI}$-other had significantly higher concentration of plasma GFAP compared to stable MCI A $\beta$ negative cases ( $p=0.01$ both) (Fig. 1c). The A $\beta$-positive MCI-other group had significantly higher GFAP levels than the A $\beta$-negative MCI-other group $(p<0.004)$ (Fig. 1c). No significant differences were present between the different $A \beta$-positive diagnostic groups or the different $A \beta$-negative diagnostic groups.

Next plasma GFAP baseline measurements were tested alone or when combined with age and/or APOE $\varepsilon 4$ status when predicting the CSF $\mathrm{A} \beta$ status. Receiver operating characteristics (ROC) curve analysis showed the greatest area under the curve (AUC) for GFAP combined with $A P O E$ \&4 status $(\mathrm{AUC}=0.86$ ) (Fig. 2a,
Table 3). This combination had a significantly higher AUC than GFAP by itself $(p=0.02)$. Adding age to the model with GFAP and APOE $\varepsilon 4$ status did not further improve the accuracy $(\mathrm{AUC}=0.86)$ (Table 3$)$. Binary logistic regression with $A \beta$-positive status as outcome showed that plasma GFAP combined with $A P O E$ \&4 status was the best predictor, with the lowest Akaike information criterion (AIC, 152; $\triangle \mathrm{AIC}=-24)($ Table 2).

The same approach was used for the identification of CSF A $342 / T$-tau-positive status. Plasma GFAP combined with $A P O E$ e4 status (with or without age) had the greatest AUC (0.84 for both) (Fig. 2b, Table 4). GFAP alone had the same AUC as in combination with age (0.80) (Fig. 2b, Table 4). Binary logistic regression with A $342 / T$-tau-positive status as outcome showed that GFAP combined with $A P O E$ was the best predictor, with the lowest AIC (157, $\triangle$ AIC = -15) (Table 4). AUCs for combinations of GFAP, APOE $\varepsilon 4$, and age were not significantly superior to the AUC of GFAP by itself (differences between AUCs not significant).

GFAP cut-off for A $\beta$-positive $(>44.7 \mathrm{pg} / \mathrm{mL})$ had a sensitivity and of $73 \%$ and $75 \%$, respectively. GFAP cutoff for A $342 /$ T-tau-positive $(>44.9 \mathrm{pg} / \mathrm{mL}$ ) had a sensitivity of $69 \%$ and a specificity of $75 \%$.

\section{Plasma GFAP can predict subsequent of conversion to $A D$ dementia}

Plasma GFAP baseline measurements were tested alone or combined with age and/or presence of at least one $A P O E \& 4$ allele for accuracy in prediction of conversion to $\mathrm{AD}$ dementia at follow-up (MCI-AD). ROC curve analysis showed the greatest AUC for plasma GFAP combined with APOE (AUC=0.86) (Fig. 2c, Table 5). Adding age to the model did not improve the accuracy
A

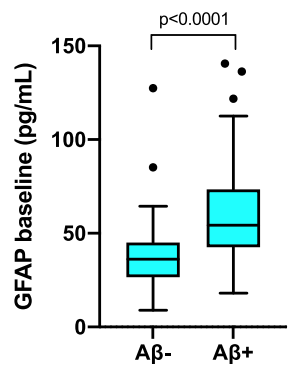

B

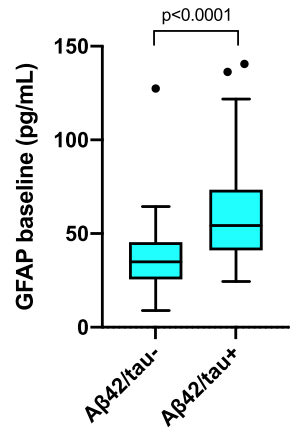

C

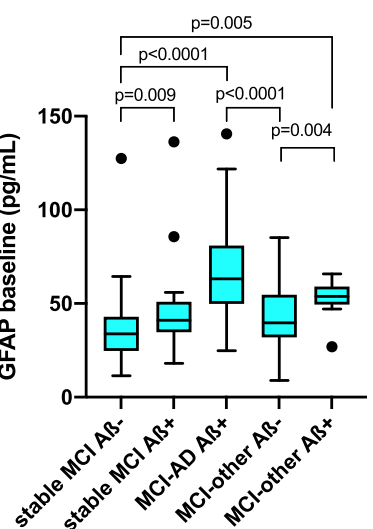

Fig. 1 a Plasma GFAP in the $A \beta$-positive $(A \beta+, C S F A \beta 42 / A \beta 40<0.07)$ and $A \beta$-negative $(A \beta-$, CSF $A \beta 42 / A \beta 40>0.07)$ groups. b Plasma GFAP in the $A \beta 42 /$ tau positive $(A \beta 42 / \pi$-tau+, CSF $A \beta 42 / T$-tau < 7.3) and A $442 /$ tau negative (A $342 /$ tau-, CSF A $\beta 42 / T$-tau > 7.3) groups. c Plasma GFAP in the stable $\mathrm{MCl}, \mathrm{MCl}-\mathrm{AD}$ and $\mathrm{MCl}$-other groups stratified by $\mathrm{A} \beta$ status. Line across represents median, box represents interquartile range (IQR), bars represent min and max value (within $\pm 1.5 \mathrm{IQR}$ ). $P$ values were calculated with univariate linear model and least significant differences (LSD) post hoc tests, with adjustments for age and sex 

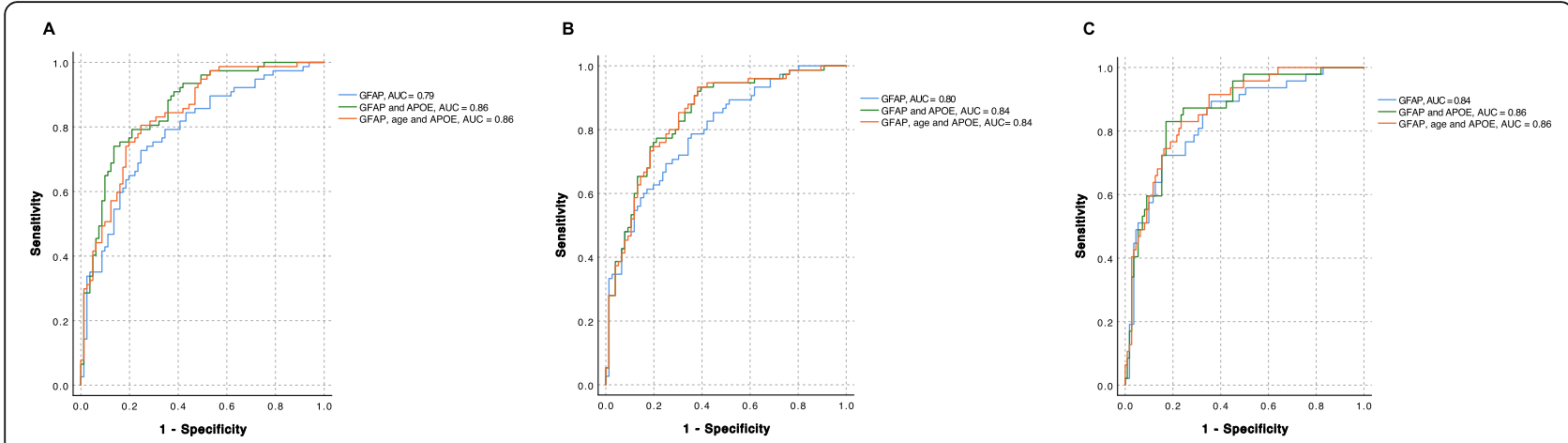

Fig. 2 ROC curves for plasma GFAP and GFAP combined with additional predictors (APOE, age) to assess accuracy when predicting A $\beta$ positivity (a), AB42/T-tau positivity (b), and MCl-AD status (c). AUC, area under the curve

$(\mathrm{AUC}=0.86)$. Binary logistic regression with $\mathrm{MCI}-\mathrm{AD}$ status as outcome showed GFAP combined with $A P O E$ $\varepsilon 4$ and age as the best predictor having the lowest AIC $(136, \triangle \mathrm{AIC}=-12)($ Table 5$)$. AUCs for combinations of GFAP, $A P O E \& 4$ and age were not significantly superior to the AUC of GFAP by itself (differences between AUCs not significant).

GFAP cut-off for an MCI-AD status $(>54.1 \mathrm{pg} / \mathrm{mL}$ ) had a sensitivity and specificity of $72 \%$ and $85 \%$, respectively.

\section{Longitudinal changes in plasma GFAP}

Slopes for plasma GFAP adjusted for age and gender showed a significant longitudinal increase in $A \beta$-negative $(\beta=2.02, p<0.0001)$, with a larger increase in the $A \beta-$ positive group compared to $A \beta$-negative $(\beta=2.06, p=$ 0.01 compared to $A \beta$-negative) (Fig. 3a).

When looking at changes over time for different cognitive groups, plasma GFAP showed a significantly higher longitudinal increase in MCI-AD and $\mathrm{A} \beta$ negative $\mathrm{MCI}$-other compared to $\mathrm{A} \beta$-negative stable MCI $(p<0.0001$ both $)$ and A $\beta$-positive stable MCI $(p=$ 0.049 and $p=0.034$, respectively) (Fig. 3b). No significant difference was seen between $\mathrm{A} \beta$-positive $\mathrm{MCI}$-other and stable MCI groups and MCI-AD and MCI-other groups.

\section{Discussion}

In this study, we assessed the potential of plasma GFAP as a diagnostic and prognostic biomarker for $\mathrm{AD}$ in a longitudinal MCI cohort. We observed that high GFAP concentration measured at baseline was a relatively strong indicator of AD pathology and could accurately predict future development of AD dementia. Differences at baseline seemed to be associated with (and possibly driven by) the $A \beta$ status; higher concentrations at baseline were in fact observed in every $A \beta$-positive subgroup compared to $A \beta$-negative ones. When looking at AUCs as measures of accuracy, the presence of at least one $A P O E \& 4$ allele moderately increased the accuracy of GFAP in detecting AD pathology, but not the accuracy in predicting conversion to $\mathrm{AD}$ dementia (no significant difference between AUCs), although the model was overall improved $(\triangle \mathrm{AIC}=-8)$. This suggests that plasma GFAP is an accurate biomarker for AD diagnosis and progression.

All cognitive groups showed a mild to moderate increasing trend over time for plasma GFAP (Fig. 3b). However, the MCI-AD and A $\beta$-negative MCI-other group showed a significantly steeper trajectory compared to the groups that remained cognitively stable. It is possible that GFAP generally increases over time because of its significant correlation with age in both $A \beta$-negative

Table 3 Combined results from binary logistic regression models and ROC curve analysis for prediction of A $\beta$-positive status

\begin{tabular}{lllllll}
\hline & $\boldsymbol{p}$ & AIC & AUC & $\mathbf{9 5 \%}$ Cl & Difference AUC ( $\boldsymbol{p})$ & $\boldsymbol{\Delta}$ AIC with GFAP \\
\hline GFAP & $<0.0001$ & 177 & 0.79 & $0.72-0.86$ & - & - \\
Age & $<0.0001$ & 208 & 0.64 & $0.56-0.73$ & - & - \\
APOE \&4 status & $<0.0001$ & 187 & 0.73 & $0.65-0.81$ & - & - \\
GFAP and age & $<0.0001$ & 179 & 0.78 & $0.71-0.86$ & $n$ & 2 \\
GFAP and APOE ع4 status & $<0.0001$ & 152 & 0.86 & $0.80-0.92$ & 0.02 & -25 \\
GFAP, age, and APOE \&4 status & $<0.0001$ & 153 & 0.86 & $0.80-0.92$ & 0.02 & -24 \\
\hline
\end{tabular}

A $\beta$-positive status was defined as CSF A $442 / 40<0.07$. AIC Akaike information criterion, AUC area under the curve, $95 \%$ CI $95 \%$ confidence intervals, difference AUC (p) difference between AUCs measured with DeLong test (AUC of GFAP used as reference), $\triangle$ AIC difference in AIC (AIC of GFAP used as reference), ns not significant 
Table 4 Combined results from binary logistic regression models and ROC curve analysis for prediction of A $342 / T$-tau-positive status

\begin{tabular}{llllll}
\hline & $\boldsymbol{p}$ & AIC & AUC & $\mathbf{9 5 \%}$ Cl & $\boldsymbol{\Delta}$ AIC with GFAP \\
\hline GFAP & $<0.0001$ & 172 & 0.80 & $0.73-0.87$ & - \\
Age & $<0.0001$ & 209 & 0.64 & $0.55-0.73$ & - \\
APOE \&4 status & $<0.0001$ & 196 & 0.68 & $0.59-0.76$ & - \\
GFAP and age & $<0.0001$ & 174 & 0.80 & $0.73-0.87$ & 2 \\
GFAP and APOE \&4 status & $<0.0001$ & 157 & 0.84 & $0.78-0.91$ & -15 \\
GFAP, age, and APOE \&4 status & $<0.0001$ & 159 & 0.84 & $0.78-0.91$ & -13 \\
\hline
\end{tabular}

A $342 / \mathrm{T}$-tau-positive status was defined as CSF A $342 / \mathrm{T}$-tau $<7.3$. AlC Akaike information criterion, AUC area under the curve, $95 \% \mathrm{Cl} 95 \%$ confidence intervals, $\triangle$ AIC difference in AIC (AIC of GFAP used as reference)

and $\mathrm{A} \beta$-positive groups $(\mathrm{A} \beta-: \mathrm{r}=0.57 ; \mathrm{A} \beta+: \quad r=0.46)$; however, this could also suggest that higher concentrations of plasma GFAP are associated to general worsening in clinical symptoms, as the steepness of the increase in GFAP was greater in all groups that evolved to dementia. The lack of significance in the difference between the $\mathrm{A} \beta$-positive $\mathrm{MCI}$-other group compared to the stable $\mathrm{MCI}$ ones is probably due to the small size of the first group $(n=9)$. This hypothesis is also reinforced by recent studies on CSF and plasma that show an inverse correlation between concentrations of GFAP and cognition [22, 27, 37]. However, one study from Verberk and colleagues [27], following cognitively normal subjects over time for evolution to dementia (AD and non$\mathrm{AD}$ combined), showed that the dementia group had no steeper trend of increase over time compared to the cognitively healthy group.

There are a series of considerations to take into account when comparing the two studies. The studies have comparable follow-up times (average 4.7 years versus median 3.6 years) and sample sizes of patients with follow-up measurements (160 versus 92 subjects). Both studies also show that patients later evolving to dementia have higher baseline GFAP concentrations. However, in Verberk et al., only $9 \%$ of patients in the longitudinal cohort developed dementia (six AD dementia, one progressive supranuclear palsy, one primary progressive aphasia), probably also due to the relatively young age of the population (average 61 years) and low percentage
(20\%) of CSF A $\beta$-positive subjects. This might have affected the power of the statistical analysis when comparing the longitudinal slopes between the dementia and cognitively healthy groups. It should also be considered that, in Verberk et al., GFAP was measured in serum, as opposed to plasma in the present study. So far, only one study has compared plasma and serum concentrations of GFAP in a traumatic brain injury cohort, with good correlation but significantly higher concentrations of GFAP in plasma [19]. Extensive head-to-head comparisons are yet to be done between the two different methods of analysis and it cannot be excluded that the presence of clotting agents in the sample might affect the results.

In our study, the finding of a strong association with $A \beta$ is not surprising, given the fact that $A D$ (which is defined by $A \beta$ deposition in plaques) is associated with astrogliosis and release of GFAP from astrocytes [3]. However, the results from previous studies with amyloid-PET imaging suggest that as the $A \beta$ load increases in brain along the course of disease, astrogliosis decreases $[9,11]$. A similar dynamic association was observed in a recent cross-sectional study on plasma GFAP, where linear positive associations between brain $A \beta$ load measured with amyloid-PET were observed in subjects at earlier stages of disease and diverged in more severe disease stages [25]. Our cohort had an adequate follow-up time (4.7 years on average); however, we cannot exclude that at a longer follow-up a similar

Table 5 Combined results from binary logistic regression models and ROC curve analysis for prediction of subsequent development of $\mathrm{AD}$ dementia (MCl-AD)

\begin{tabular}{llllll}
\hline & $\boldsymbol{p}$ & AIC & AUC & 95\% Cl & $\boldsymbol{\Delta}$ AIC with GFAP \\
\hline GFAP & $<0.0001$ & 148 & 0.84 & $0.77-0.91$ & - \\
Age & $<0.0001$ & 171 & 0.73 & $0.64-0.81$ & - \\
APOE \&4 status & $<0.0001$ & 177 & 0.67 & $0.58-0.76$ & - \\
GFAP and age & $<0.0001$ & 145 & 0.83 & $0.76-0.90$ & -3 \\
GFAP and APOE \&4 status & $<0.0001$ & 140 & 0.86 & $0.80-0.93$ & -8 \\
GFAP, age, and APOE \&4 status & $<0.0001$ & 136 & 0.86 & $0.81-0.92$ & -12 \\
\hline
\end{tabular}

AIC Akaike information criterion, AUC area under the curve, 95\% CI 95\% confidence intervals, $\triangle$ AIC difference in AIC (AIC of GFAP used as reference) 

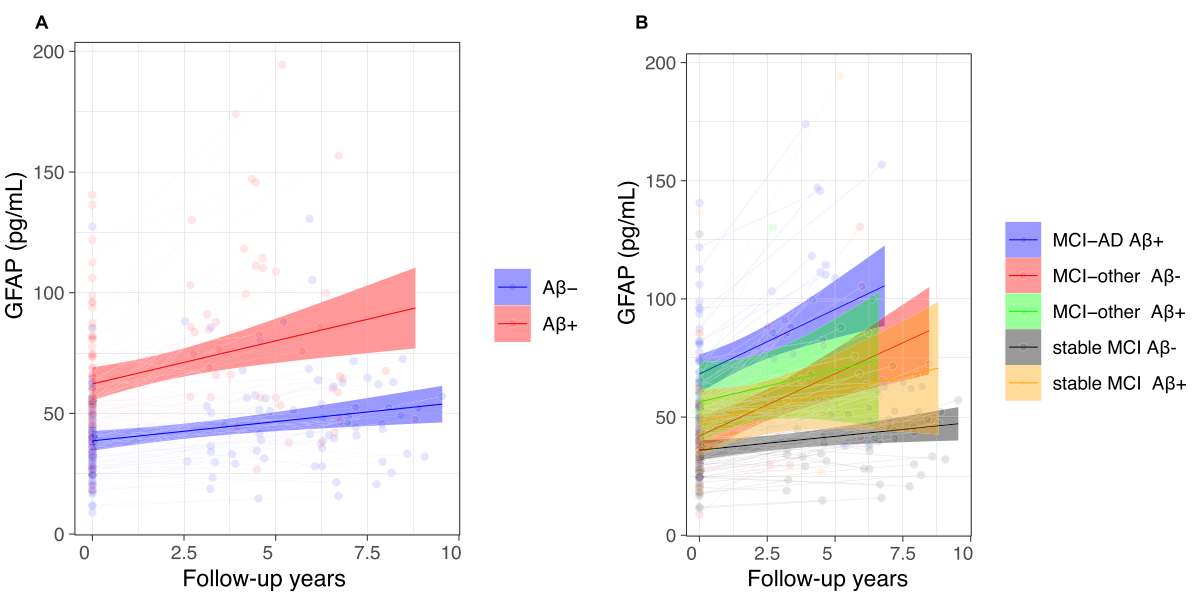

Fig. 3 Longitudinal slopes for plasma GFAP from linear mixed-effects model adjusted for age and sex. $X$-axis represents time between baseline and follow-up plasma sampling; $y$-axis represents plasma concentrations in $\mathrm{pg} / \mathrm{mL}$. Plasma GFAP measurements were stratified by A $\beta$-positive $(A \beta+)$ status defined by CSF $A \beta 42 / 40<0.07$ (a). Slopes for $A \beta$-positive subjects were significantly steeper than $A \beta$-negative $(p=0.007)$. In $\mathbf{b}$, plasma GFAP measurements were stratified by clinical diagnosis at follow-up and A $\beta$ status. GFAP slopes in MCl-AD and A $\beta$-negative MCl-other subjects were significantly steeper compared to stable $\mathrm{MCl} A \beta$-negative $(p<0.0001$ both) and stable $\mathrm{MCl} A \beta$-positive $(p=0.049$, $p=0.037$, respectively)

association could be observed. Although GFAP is not specific for $\mathrm{AD}$, the high accuracy showed in detecting $\mathrm{AD}$ pathology and conversion to $\mathrm{AD}$ dementia suggest that plasma GFAP could be a useful indicator of the astroglial activation component of the multifaceted pathology in AD. In our cohort, plasma GFAP also showed a significant negative correlation to CSF $A \beta 42 / 40$ in $A \beta$ negative subjects (Table 2), indicating that lower values of CSF A $\beta 42 / 40$ (still in the normal range) are associated with higher plasma GFAP. This also suggests that plasma GFAP could be very early marker in the predementia phase, like that of our patients at baseline. The strong association with $A \beta$ status also suggests that plasma GFAP could add to and complement the information from plasma $A \beta$, as immunoassay measurements of $A \beta 42$ and $A \beta 40$ (and their ratio) still require further optimization [38-40].

\section{Limitations}

One limitation of our study was the lack of a cognitively healthy control group. However, we did comparisons between the $\mathrm{AD}$ group and the stable MCI $\mathrm{A} \beta$-negative, which had a non-progressing type of cognitive impairment and no objectifiable evidence of underlying neurodegenerative disease. Another limitation is the lack of PET imaging data for determination of $A \beta$ status; we have, however, defined $A \beta$-positive patients based on the CSF A $342 / 40$ ratio, which has consistently shown a strong association with brain $A \beta$ load evaluated by PET or at neuropathology $[41,42]$.

\section{Conclusions}

In conclusion, our results show that plasma GFAP is associated to AD-type pathology and can accurately predict clinical progression to $\mathrm{AD}$ dementia, making it a potential candidate to add to the blood-based biomarker panel for AD.

\section{Abbreviations}

$A \beta$ : Amyloid $\beta$; AD: Alzheimer's disease; AIC: Akaike information criterion; AUC: Area under the curve; CBS: Corticobasal syndrome; CSF: Cerebrospinal fluid; DLB: Lewy body dementia; MCI: Mild cognitive impairment; PSP: Progressive supranuclear palsy; P-tau181: Phosphorylated tau; ROC: Receiver operating characteristic; Simoa: Single molecule array; Ttau: Total tau; VaD: Vascular dementia

\section{Acknowledgements}

Not applicable.

\section{Authors' contributions}

CC analyzed the samples, performed the data analysis, and wrote the manuscript. SJ analyzed the samples and supervised the statistical analysis. $\mathrm{JH}$ selected and diagnosed the patients included in the study. $\mathrm{HZ}$ and $\mathrm{KB}$ were responsible for the CSF biomarkers analyses. NMC performed the statistical analysis. $\mathrm{OH}$ designed the study. All authors reviewed and approved the manuscript.

\section{Funding}

Work at the authors' research center was supported by the Swedish Research Council, the Knut and Alice Wallenberg Foundation, the Marianne and Marcus Wallenberg Foundation, the Strategic Research Area MultiPark (Multidisciplinary Research in Parkinson's disease) at Lund University, the Swedish Alzheimer Foundation, the Swedish Brain Foundation, The Parkinson foundation of Sweden, The Parkinson Research Foundation, the Skåne University Hospital Foundation, the Wallenberg Center for Molecular Medicine, The Medical Faculty at Lund University, Region Skåne, the Swedish Medical Association, the Konung Gustaf V:s och Drottning Victorias Frimurarestiftelse, the Bundy Academy, and the Swedish federal government under the ALF agreement. Open Access funding provided by Lund University. 


\section{Availability of data and materials}

Anonymized data will be shared by request from a qualified academic investigator for the sole purpose of replicating procedures and results presented in the article and as long as data transfer is in agreement with EU legislation on the general data protection regulation and decisions by the Ethical Review Board of Sweden and Region Skåne, which should be regulated in a material transfer agreement.

\section{Declarations}

\section{Ethics approval and consent to participate}

The study was approved by the Ethics Committee at the University of Lund and the patients and/or their relatives gave their informed consent (for research).

\section{Consent for publication}

Not applicable.

\section{Competing interests}

$\mathrm{HZ}$ has served at scientific advisory boards for Denali, Roche Diagnostics, Wave, Samumed, Siemens Healthineers, Pinteon Therapeutics, and CogRx; has given lectures in symposia sponsored by Fujirebio, Alzecure, and Biogen; and is a co-founder of Brain Biomarker Solutions in Gothenburg AB (BBS), which is a part of the GU Ventures Incubator Program (outside submitted work). KB has served as a consultant, at advisory boards, or at data monitoring committees for Abcam, Axon, Biogen, JOMDD/Shimadzu. Julius Clinical, Lilly, MagQu, Novartis, Roche Diagnostics, and Siemens Healthineers, and is a co-founder of Brain Biomarker Solutions in Gothenburg AB (BBS) (outside submitted work). $\mathrm{OH}$ has acquired research support (for the institution) from AVID Radiopharmaceuticals, Biogen, Eli Lilly, Eisai, GE Healthcare, Pfizer, and Roche. In the past 2 years, he has received consultancy/speaker fees from AC Immune, Alzpath, Biogen, Cerveau, and Roche. The other authors declare no conflict of interest.

\section{Author details}

'Clinical Memory Research Unit, Department of Clinical Sciences, Lund University, Lund, Sweden. ${ }^{2}$ Memory Clinic, Skåne University Hospital, Malmö, Sweden. ${ }^{3}$ Department of Psychiatry and Neurochemistry, Institute of Neuroscience and Physiology, The Sahlgrenska Academy at the University of Gothenburg, Mölndal, Sweden. ${ }^{4}$ Clinical Neurochemistry Laboratory, Sahlgrenska University Hospital, Mölndal, Sweden. ${ }^{5}$ Department of Neurodegenerative Disease, UCL Institute of Neurology, Queen Square, London, UK. ${ }^{6}$ UK Dementia Research Institute at UCL, London, UK. ${ }^{7}$ Department of Neurology, Skåne University Hospital, Lund, Sweden. ${ }^{8}$ Wallenberg Center for Molecular Medicine, Lund University, Lund, Sweden.

Received: 26 November 2020 Accepted: 9 March 2021

Published online: 27 March 2021

\section{References}

1. World Health Organization W. Global Dementia Observatory, Global action plan on the public health response to dementia 2017-2025 2017

2. Reiman EM, Quiroz YT, Fleisher AS, Chen K, Velez-Pardo C, Jimenez-Del-Rio $\mathrm{M}$, et al. Brain imaging and fluid biomarker analysis in young adults at genetic risk for autosomal dominant Alzheimer's disease in the presenilin 1 E280A kindred: a case-control study. Lancet Neurol. 2012;11(12):1048-56. https://doi.org/10.1016/S1474-4422(12)70228-4

3. Osborn LM, Kamphuis W, Wadman WJ, Hol EM. Astrogliosis: an integral player in the pathogenesis of Alzheimer's disease. Prog Neurobiol. 2016;144: 121-41. https://doi.org/10.1016/j.pneurobio.2016.01.001.

4. Mathur R, Ince PG, Minett T, Garwood CJ, Shaw PJ, Matthews FE, Brayne C, Simpson JE, Wharton SB, on behalf of the MRC Cognitive Function and Ageing Neuropathology Study Group. A reduced astrocyte response to beta-amyloid plaques in the ageing brain associates with cognitive impairment. Plos One. 2015;10(2):e0118463. https://doi.org/10.1371/journal. pone.0118463.

5. Garwood CJ, Pooler AM, Atherton J, Hanger DP, Noble W. Astrocytes are important mediators of A -induced neurotoxicity and tau phosphorylation in primary culture. Cell Death Dis. 2011;2(6):e167-e.

6. DaRocha-Souto B, Scotton TC, Coma M, Serrano-Pozo A, Hashimoto T, Sereno L, et al. Brain oligomeric beta-amyloid but not total amyloid plaque burden correlates with neuronal loss and astrocyte inflammatory response in amyloid precursor protein/tau transgenic mice. J Neuropathol Exp Neurol. 2011;70(5):360-76. https://doi.org/10.1097/NEN.0b013e318217a118.

7. Munger EL, Edler MK, Hopkins WD, Ely JJ, Erwin JM, Perl DP, Mufson EJ, Hof PR, Sherwood CC, Raghanti MA. Astrocytic changes with aging and Alzheimer's disease-type pathology in chimpanzees. J Comp Neurol. 2019; 527(7):1179-95. https://doi.org/10.1002/cne.24610.

8. Sollvander S, Nikitidou E, Brolin R, Soderberg L, Sehlin D, Lannfelt L, et al. Accumulation of amyloid-beta by astrocytes result in enlarged endosomes and microvesicle-induced apoptosis of neurons. Mol Neurodegener. 2016; 11(1):38. https://doi.org/10.1186/s13024-016-0098-z.

9. Carter SF, Schöll M, Almkvist O, Wall A, Engler H, Långström B, et al. Evidence for astrocytosis in prodromal Alzheimer disease provided by $11 \mathrm{C}$ deuterium-L-deprenyl: a multitracer PET paradigm combining 11CPittsburgh compound B and 18F-FDG. J Nuclear Med. 2012;53(1):37-46. https://doi.org/10.2967/jnumed.110.087031.

10. Schöll M, Carter SF, Westman E, Rodriguez-Vieitez E, Almkvist O, Thordardottir S, Wall A, Graff C, Långström B, Nordberg A. Early astrocytosis in autosomal dominant Alzheimer's disease measured in vivo by multitracer positron emission tomography. Sci Rep. 2015;5(1):16404. https://doi. org/10.1038/srep16404.

11. Rodriguez-Vieitez E, Saint-Aubert L, Carter SF, Almkvist O, Farid K, Schöll M, Chiotis K, Thordardottir S, Graff C, Wall A, Långström B, Nordberg A. Diverging longitudinal changes in astrocytosis and amyloid PET in autosomal dominant Alzheimer's disease. Brain. 2016;139(Pt 3):922-36. https://doi.org/10.1093/brain/awv404.

12. Abu-Rumeileh $S$, Steinacker P, Polischi B, Mammana A, Bartoletti-Stella A, Oeckl P, Baiardi S, Zenesini C, Huss A, Cortelli P, Capellari S, Otto M, Parchi P. CSF biomarkers of neuroinflammation in distinct forms and subtypes of neurodegenerative dementia. Alzheimers Res Ther. 2019;12(1):2. https://doi. org/10.1186/s13195-019-0562-4.

13. Ishiki A, Kamada M, Kawamura Y, Terao C, Shimoda F, Tomita N, Arai H, Furukawa K. Glial fibrillar acidic protein in the cerebrospinal fluid of Alzheimer's disease, dementia with Lewy bodies, and frontotemporal lobar degeneration. J Neurochem. 2016;136(2):258-61. https://doi.org/10.1111/ jnc.13399.

14. Jesse $S$, Steinacker $P$, Cepek L, von Arnim CA, Tumani H, Lehnert S, et al. Glial fibrillary acidic protein and protein S-100B: different concentration pattern of glial proteins in cerebrospinal fluid of patients with Alzheimer's disease and Creutzfeldt-Jakob disease. J Alzheimers Dis. 2009;17(3):541-51. https://doi.org/10.3233/JAD-2009-1075.

15. Wallin A, Blennow K, Rosengren LE. Glial fibrillary acidic protein in the cerebrospinal fluid of patients with dementia. Dementia. 1996;7(5):267-72. https://doi.org/10.1159/000106891.

16. Chen $\mathrm{CH}$, Cheng YW, Chen YF, Tang SC, Jeng JS. Plasma neurofilament light chain and glial fibrillary acidic protein predict stroke in CADASIL. J Neuroinflammation. 2020;17(1):124. https://doi.org/10.1186/s12974-020-01 813-5.

17. Elahi FM, Casaletto KB, La Joie R, Walters SM, Harvey D, Wolf A, et al. Plasma biomarkers of astrocytic and neuronal dysfunction in early- and late-onset Alzheimer's disease. Alzheimers Dement. 2020;16(4):681-95. https://doi.org/1 0.1016/j.jalz.2019.09.004.

18. Heller C, Foiani MS, Moore K, Convery R, Bocchetta M, Neason M, Cash DM, Thomas D, Greaves CV, Woollacott IOC, Shafei R, van Swieten JC, Moreno F, Sanchez-Valle R, Borroni B, Laforce Jr R, Masellis M, Tartaglia MC, Graff C, Galimberti D, Rowe JB, Finger E, Synofzik M, Vandenberghe R, de Mendonca A, Tagliavini F, Santana I, Ducharme S, Butler CR, Gerhard A, Levin J, Danek A, Frisoni G, Sorbi S, Otto M, Heslegrave AJ, Zetterberg H, Rohrer JD. Plasma glial fibrillary acidic protein is raised in progranulin-associated frontotemporal dementia. J Neurol Neurosurg Psychiatry. 2020;91(3):263-70. https://doi.org/10.1136/jnnp-2019-321954.

19. Huebschmann NA, Luoto TM, Karr JE, Berghem K, Blennow K, Zetterberg $\mathrm{H}$, Ashton NJ, Simrén J, Posti JP, Gill JM, Iverson GL. Comparing glial fibrillary acidic protein (GFAP) in serum and plasma following mild traumatic brain injury in older adults. Front Neurol. 2020;11:1054. https://doi.org/10.3389/ fneur.2020.01054.

20. Mayer CA, Brunkhorst R, Niessner M, Pfeilschifter W, Steinmetz H, Foerch C. Blood levels of glial fibrillary acidic protein (GFAP) in patients with neurological diseases. Plos One. 2013;8(4):e62101-e.

21. Oeckl P, Halbgebauer S, Anderl-Straub S, Steinacker P, Huss AM, Neugebauer $\mathrm{H}$, et al. Glial fibrillary acidic protein in serum is increased in 
Alzheimer's disease and correlates with cognitive impairment. J Alzheimer Dis. 2019;67(2):481-8. https://doi.org/10.3233/JAD-180325.

22. Rajan KB, Aggarwal NT, McAninch EA, Weuve J, Barnes LL, Wilson RS, et al. Remote blood biomarkers of longitudinal cognitive outcomes in a population study. Ann Neurol. 2020.

23. van Ballegoij WJC, van de Stadt SIW, Huffnagel IC, Kemp S, Willemse EAJ, Teunissen CE, et al. Plasma NfL and GFAP as biomarkers of spinal cord degeneration in adrenoleukodystrophy. Ann Clin Transl Neurol. 2020;7(11): 2127-36. https://doi.org/10.1002/acn3.51188.

24. Verberk IMW, Thijssen E, Koelewijn J, Mauroo K, Vanbrabant J, de Wilde A, Zwan MD, Verfaillie SCJ, Ossenkoppele R, Barkhof F, van Berckel BNM, Scheltens P, van der Flier WM, Stoops E, Vanderstichele HM, Teunissen CE. Combination of plasma amyloid beta(1-42/1-40) and glial fibrillary acidic protein strongly associates with cerebral amyloid pathology. Alzheimers Res Ther. 2020;12(1):118. https://doi.org/10.1186/s13195-020-00682-7.

25. Asken BM, Elahi FM, La Joie R, Strom A, Staffaroni AM, Lindbergh CA, et al. Plasma glial fibrillary acidic protein levels differ along the spectra of amyloid burden and clinical disease stage. J Alzheimers Dis. 2020;78(1):265-76. https://doi.org/10.3233/JAD-200755.

26. Chatterjee P, Pedrini S, Stoops E, Goozee K, Villemagne VL, Asih PR, Verberk IMW, Dave P, Taddei K, Sohrabi HR, Zetterberg H, Blennow K, Teunissen CE, Vanderstichele HM, Martins RN. Plasma glial fibrillary acidic protein is elevated in cognitively normal older adults at risk of Alzheimer's disease. Transl Psychiatry. 2021;11(1):27. https://doi.org/10.1038/s41398-020-01137-1.

27. Verberk IMW, Laarhuis MB, van den Bosch KA, Ebenau JL, van Leeuwenstijn M, Prins ND, et al. Serum markers glial fibrillary acidic protein and neurofilament light for prognosis and monitoring in cognitively normal older people: a prospective memory clinic-based cohort study. Lancet Healthy Longevity.

28. Hertze J, Minthon L, Zetterberg H, Vanmechelen E, Blennow K, Hansson O. Evaluation of CSF biomarkers as predictors of Alzheimer's disease: a clinical follow-up study of 4.7 years. J Alzheimers Dis. 2010;21(4):1119-28. https:// doi.org/10.3233/JAD-2010-100207.

29. Petersen RC. Mild cognitive impairment as a diagnostic entity. J Intern Med. 2004;256(3):183-94. https://doi.org/10.1111/j.1365-2796.2004.01388.x.

30. McKhann G, Drachman D, Folstein M, Katzman R, Price D, Stadlan EM. Clinical diagnosis of Alzheimer's disease: report of the NINCDS-ADRDA Work Group under the auspices of Department of Health and Human Services Task Force on Alzheimer's Disease. Neurology. 1984;34(7):939-44. https://doi. org/10.1212/WNL.34.7.939.

31. Roman GC, Tatemichi TK, Erkinjuntti T, Cummings JL, Masdeu JC, Garcia JH, Amaducci L, Orgogozo JM, Brun A, Hofman A, Moody DM, O'Brien MD, Yamaguchi T, Grafman J, Drayer BP, Bennett DA, Fisher M, Ogata J, Kokmen E, Bermejo F, Wolf PA, Gorelick PB, Bick KL, Pajeau AK, Bell MA, DeCarli C, Culebras A, Korczyn AD, Bogousslavsky J, Hartmann A, Scheinberg P. Vascular dementia: diagnostic criteria for research studies. Report of the NINDS-AIREN International Workshop. Neurology. 1993;43(2):250-60. https:// doi.org/10.1212/WNL.43.2.250.

32. McKeith IG, Perry EK, Perry RH. Report of the second dementia with Lewy body international workshop: diagnosis and treatment. Consortium on Dementia with Lewy Bodies. Neurology. 1999;53(5):902-5. https://doi.org/1 0.1212/WNL.53.5.902.

33. Litvan I, Agid Y, Calne D, Campbell G, Dubois B, Duvoisin RC, Goetz CG, Golbe LI, Grafman J, Growdon JH, Hallett M, Jankovic J, Quinn NP, Tolosa E, Zee DS. Clinical research criteria for the diagnosis of progressive supranuclear palsy (Steele-Richardson-Olszewski syndrome): report of the NINDS-SPSP international workshop. Neurology. 1996;47(1):1-9. https://doi. org/10.1212/WNL.47.1.1.

34. Hoglinger GU, Respondek G, Stamelou M, Kurz C, Josephs KA, Lang AE, et al. Clinical diagnosis of progressive supranuclear palsy: the movement disorder society criteria. Mov Disord. 2017;32(6):853-64. https://doi.org/10.1002/mds.26987.

35. Blennow K, Hampel H, Weiner M, Zetterberg H. Cerebrospinal fluid and plasma biomarkers in Alzheimer disease. Nat Rev Neurol. 2010;6(3):131-44. https://doi.org/10.1038/nrneurol.2010.4.

36. Olsson A, Vanderstichele H, Andreasen N, De Meyer G, Wallin A, Holmberg $B$, et al. Simultaneous measurement of beta-amyloid(1-42), total tau, and phosphorylated tau (Thr181) in cerebrospinal fluid by the XMAP technology. Clin Chem. 2005;51(2):336-45. https://doi.org/10.1373/clinchem.2004.039347.

37. Teitsdottir UD, Jonsdottir MK, Lund SH, Darreh-Shori T, Snaedal J, Petersen $\mathrm{PH}$. Association of glial and neuronal degeneration markers with Alzheimer's disease cerebrospinal fluid profile and cognitive functions. Alzheimers Res Ther. 2020;12(1):92. https://doi.org/10.1186/s13195-020-00657-8.
38. Janelidze $S$, Stomrud E, Palmqvist $S$, Zetterberg $H$, van Westen $D$, Jeromin A, Song L, Hanlon D, Tan Hehir CA, Baker D, Blennow K, Hansson O. Plasma $\beta$ amyloid in Alzheimer's disease and vascular disease. Sci Rep. 2016;6(1): 26801. https://doi.org/10.1038/srep26801.

39. Verberk IMW, Slot RE, Verfaillie SCJ, Heijst H, Prins ND, van Berckel BNM, Scheltens P, Teunissen CE, van der Flier WM. Plasma amyloid as prescreener for the earliest Alzheimer pathological changes. Ann Neurol. 2018;84(5):64858. https://doi.org/10.1002/ana.25334.

40. Olsson B, Lautner R, Andreasson U, Ohrfelt A, Portelius E, Bjerke M, et al. CSF and blood biomarkers for the diagnosis of Alzheimer's disease: a systematic review and meta-analysis. Lancet Neurol. 2016;15(7):673-84. https://doi. org/10.1016/S1474-4422(16)00070-3.

41. Janelidze S, Pannee J, Mikulskis A, Chiao P, Zetterberg H, Blennow K, Hansson O. Concordance between different amyloid immunoassays and visual amyloid positron emission tomographic assessment. JAMA Neurol. 2017;74(12):1492-501. https://doi.org/10.1001/jamaneurol.2017.2814.

42. Shaw LM, Arias J, Blennow K, Galasko D, Molinuevo JL, Salloway S, Schindler S, Carrillo MC, Hendrix JA, Ross A, Illes J, Ramus C, Fifer S. Appropriate use criteria for lumbar puncture and cerebrospinal fluid testing in the diagnosis of Alzheimer's disease. Alzheimers Dement. 2018;14(11):1505-21. https://doi. org/10.1016/j.jalz.2018.07.220.

\section{Publisher's Note}

Springer Nature remains neutral with regard to jurisdictional claims in published maps and institutional affiliations.
Ready to submit your research? Choose BMC and benefit from:

- fast, convenient online submission

- thorough peer review by experienced researchers in your field

- rapid publication on acceptance

- support for research data, including large and complex data types

- gold Open Access which fosters wider collaboration and increased citations

- maximum visibility for your research: over $100 \mathrm{M}$ website views per year

At BMC, research is always in progress.

Learn more biomedcentral.com/submissions 